\title{
Magnetic bentonite nanocomposite for removal of amoxicillin from wastewater samples using response surface methodology before determination by high performance liquid chromatography
}

\author{
Mohammad Reza Rezaei Kahkha ${ }^{\text {a, }}$, Ali Faghihi Zarandi ${ }^{\text {, Nahid Shafighia }}{ }^{\text {, Saeedeh Kosaria }}$ \\ and Batool Rezaei Kahkha ${ }^{a}$
}

${ }^{a}$ Department of Environmental Health Engineering, Faculty of Health, Zabol University of Medical Sciences, Zabol.Iran. ${ }^{b}$ Department of Occupational Health Engineering, Faculty of Health, Kerman University of Medical Sciences, Kerman. Iran.

A R T I C L E I N F O :
Received 11 Jun 2020
Revised form 5 Aug 2020
Accepted 28 Aug 2020
Available online 29 Sep 2020
----------------
Keywords:
High performance liquid
chromatography,
Amoxicillin removal,
Response surface methodology (RSM),
Central composition design,
Magnetic bentonite nanocomposite

A R T I C L E I N F O :

Revised form 5 Aug 2020

Accepted 28 Aug 2020

Available online 29 Sep 2020

Keywords:

High performance liquid

Response surface methodology (RSM),

Magnetic bentonite nanocomposite

\begin{abstract}
A B S T R A C T
In this study, feasibility of magnetic bentonite nanocomposite for removal of amoxicillin from wastewater samples was evaluated by high performance liquid chromatography (HPLC). Magnetic bentonite synthesized by co-precipitation of bentonite and $\mathrm{Fe}_{3} \mathrm{O}_{4}$ and used for removal of amoxicillin from water samples. Response surface methodology on central composition design (CCD) was applied for designing of experiment and building of model. Three factors including $\mathrm{pH}$, adsorbent dose and temperature were studied and used for quadratic equation model to prediction of optimal points. By solving the equation and considering regression coefficient $\left(\mathrm{R}^{2}\right.$ $=0.98$ ). The optimal points of main parameters were obtained as a $\mathrm{pH}$ of 4.68 , the adsorbent dosage of $1.50 \mathrm{~g}$ and the temperature of $48.9^{\circ} \mathrm{C}$. Results showed that three factor are significant on removal efficiency and experimental data are in good agreement with predicted data. Proposed methods were used to analysis of amoxicillin in three real samples.
\end{abstract}

\section{Introduction}

Nowadays, antibiotic residual is a serious concern for many of environmental researchers. Because of insufficient ability of conventional sewage treatment, some antibiotics such as ampicillin, erythromycin, tetracycline and penicillin are not even removed in sewage treatment processes and cause many environmental hazards [1]. Recent

\footnotetext{
* Corresponding Author: Mohammad Reza Rezaei Kahkha Email: m.r.rezaei.k@gmail.com https://doi.org/10.24200/amecj.v3.i03.108
}

studies have shown that some antibiotics have toxic effects on the life of microorganisms and, over the long term, have undesirable effects on ecological sustainability [2]. Amoxicillin $\left(\mathrm{C}_{16} \mathrm{H}_{19} \mathrm{~N}_{3} \mathrm{O}_{5} \mathrm{~S}_{3}\right)$ is a $\beta$ - lactam antibiotic with a molecular weight of 365 gram per mole is used to treat bacterial infections [3]. The concentration of this type of antibiotics groups in surface waters is $48 \mathrm{ng} \mathrm{L}^{-1}$ and in the hospital sewage between $28-82 \mathrm{mg} \mathrm{L}^{-1}$ have been reported. In many pharmaceutical effluent output higher concentration of these drugs can also be found. Several methods such as; the ozonation [4], 
the Fenton process [5], electrochemical methods [6], the nano filtration [7] and the adsorption process [8] were applied for removal of antibiotics from aqueous environments samples. Absorption is one of the most effective methods to removal of antibiotics compounds from water and sewage even at low concentrations (less than $1 \mathrm{mg} \mathrm{L}^{-1}$ ). Adsorption is very simple and low cost method in comparison to other techniques that applied for removal of common pollutants from aqueous samples [9]. Natural clay compounds are one of the best adsorbents to removal of contaminants from air and water samples. This ability obtained from their high surface area, the porous structure, the chemical stability, and their layered structure. Bentonite is a natural clay that used as an adsorbent to removal of pollutants from water and wastewater samples. Response surface methodology (RSM) is appropriate technique that used in many fields [10]. The main objective of RSM is to determine optimum operating conditions for the system or designated area of the practical satisfaction [11]. Experimental data points were obtained during our optimization and used to build a model for CCD which was ideal for sequential testing and allows the right amount of information to test the lack of fit a large number of unusual design points. In this study, removal of amoxicillin by nanocomposite made of multi-walled carbon nanotubes and iron nanoparticles were studied. Design of Experiments were conducted using the RSM as well as factors affecting on absorption process of amoxicillin such as $\mathrm{pH}$, amount of adsorbent, and the temperature were optimized. Finally, the data obtained from experiments compared with model output to optimize and predict the results. The concentration of amoxicillin determined by high performance liquid chromatography. HPLC is simple, accurate and precise technique that used for separation, identification and analysis of drugs. It can be successfully and efficiently adopted for routine quality control analysis of drugs in bulk and pharmaceutical dosage form. It can also be used in combination with other analytical methods to further elucidate the components of mixtures.

\section{Material and methods}

\subsection{Apparatus and reagent}

The measurement of amoxicillin was performed using high performance liquid chromatography accessory (CECIL Corporation, HPLC, England) equipped $\mathrm{ACE} \mathrm{C}_{18}$ column and UV-VIS detector at $230 \mathrm{~nm}$. The mobile phase is ACN: water (60:40). Analytical grade of different reagents such as; $\mathrm{HCl}$ and $\mathrm{NaOH}$ were purchased from Merck (Darmstadt, Germany). The amoxicillin was prepared from Aldrich chemical Co. HPLC grade of acetonitrile and water purchased from Sharloa (Espain). Bentonite clay was purchased and from Merck (Darmstadt, Germany) and used for further work. The bentonite samples were powdered and sieved by 80 -mesh sieve and washed with double distilled water (DDW) for 4 times before using by procedure.

\subsection{Synthesize of adsorbent}

Synthesize of magnetic bentonite are performed by co-precipitation methods by Hashem et al. First, $20 \mathrm{~g}$ of bentonite was added into $100 \mathrm{ml}$ of distilled water containing $\mathrm{FeCl}_{2}\left(0.02 \mathrm{~mol} \mathrm{~L}^{-1}\right)$ and $\mathrm{FeCl}_{3}(0.04 \mathrm{~mol}$ $\mathrm{L}^{-1}$ ). The $\mathrm{pH}$ of solution was set around 10 by adding $\mathrm{NH}_{4} \mathrm{OH}$ buffer solution $\left(1 \mathrm{~mol} \mathrm{~L}^{-1}\right)$ and stirred for 30 min at $300 \mathrm{rpm}$. Next, $40 \mathrm{ml}$ of $\mathrm{HNO}_{3}$ solution $(2 \mathrm{M})$ was added with stirring for 5 minutes and then 60 $\mathrm{ml}$ of $\mathrm{Fe}\left(\mathrm{NO}_{3}\right)_{3}$ solution $(0.35 \mathrm{M})$ was added to the previous solution and solution boiled for one hour. After settling suspension, the residual was filtered and solid of magnetic bentonite was separated by washing of DDW for 3-5 times. Finally, the product was heated in an oven at $80^{\circ} \mathrm{C}$ for $24 \mathrm{~h}$ [12].

\subsection{Removal Procedure}

Experiments were performed with the central composite design (CCD) methodology. A standard solution of $1000 \mathrm{mg} \mathrm{L}^{-1}$ amoxicillin was prepared by dissolving of $1 \mathrm{~g}$ of amoxicillin in 1 liter of deionized water. All standard working prepared from this solution. Experiments were performed at a batch reactor in $500 \mathrm{ml}$ beaker that containing of $50 \mathrm{ml}$ of amoxicillin concentration and the solution was shaked for the 30 minutes in incubation shaker at $200 \mathrm{rpm}$ by controlling of temperature. The $\mathrm{pH}$ 
of the solution was adjusted by adding $0.1 \mathrm{M}$ of $\mathrm{NaOH}$ and $\mathrm{HCl}$. After completion of experiments, magnetic nanocomposite was removed by an external magnet and remaining amoxicillin was measured. The removal percentage of Amoxicillin (\% removal) was calculated as Equation 1:

$$
\% \text { Removal }=\frac{C e-c 0}{C 0} * 100
$$

(Eq. 1)

Where $\mathrm{Ce}$ and $\mathrm{C}_{0}$ are initial and final Amoxicillin concentration $\left(\mathrm{mg} \mathrm{l}^{-1}\right)$ in solution, respectively.

\subsection{Experimental design}

A central composition design (CCD) was carried out in this research for evaluate the variables for adsorption of amoxicillin from aqueous solution using in a batch reactor. The CCD method for three variables $(\mathrm{pH}$, amount of nanocomposite and temperature), with two levels (the minimum and maximum) was used as experimental design model. In the experimental design model, the $\mathrm{pH}$ between
2-9, the adsorbent dosage from $0.5 \mathrm{~g}$ to $1.5 \mathrm{~g}$ and the temperature between $20-60^{\circ} \mathrm{C}$ were employed as the input variables. Percentage removal of amoxicillin was the response of the system. Table. 1 showed the experimental design matrix that obtained from CCD procedure. The amoxicillin concentration determined by HPLC. The quadratic equation model for predicting the optimal point of adsorption processes was expressed by Equation 2 .

$$
Y=\beta i+\sum_{\mathrm{i}=1}^{\mathrm{k}} \beta \mathrm{ixi}+\sum_{\mathrm{i}=1}^{\mathrm{k}} \beta \mathrm{iixi}^{2}+\sum_{\mathrm{i}=0}^{\mathrm{k}} \sum_{\mathrm{j}=\mathrm{i}+1}^{\mathrm{k}} \beta \mathrm{xixj}+\epsilon
$$$$
\text { (Eq.2) }
$$

Where $\mathrm{Y}$ is the response of the system and $\mathrm{X}_{\mathrm{i}}$ and $\mathrm{X}_{\mathrm{J}}$ are the variables of action. $\mathrm{R}^{2}$ is coefficient of determination of polynomial model. The statistical significance was verified with adequate precision ratio and by the F-test. Design expert (version 8) program was used for regression and graphical analysis. A total of 19 experiments were necessary to estimate of the full model (Table 1)

Table 1. Central composite design matrix with experimental and predicted values

\begin{tabular}{cccccc}
\hline Run & $\mathbf{p H}$ & $\mathbf{T}\left({ }^{\mathbf{c}} \mathbf{)}\right.$ & adsorbent( $)$ & Actual Value (\%) & Predicted Value(\%) \\
\hline 1 & 5.5 & 45 & 1 & 98 & 92.20 \\
\hline 2 & 11.39 & 45.00 & 1.00 & 20 & 19.20 \\
\hline 3 & 5.50 & 45.00 & 1.00 & 96 & 92.20 \\
\hline 4 & 9.00 & 65.00 & .050 & 57 & 60.29 \\
\hline 5 & 5.50 & 45.00 & 1.00 & 83 & 92.20 \\
\hline 6 & 5.50 & 45.00 & 1.84 & 95 & 92.20 \\
\hline 7 & 2.00 & 65.00 & 1.50 & 99 & 91.64 \\
\hline 8 & 2.00 & 25.00 & 1.50 & 97 & 77.97 \\
\hline 9 & 5.50 & 45.00 & 1.00 & 98 & 92.20 \\
\hline 10 & 5.50 & 11.36 & 1.00 & 86 & 65.08 \\
\hline 11 & 2.00 & 65.00 & 0.50 & 83 & 100 \\
\hline 12 & 5.50 & 45.00 & 0.16 & 90 & 66.82 \\
\hline 13 & 9.00 & 65 & 1.50 & 70 & 74.58 \\
\hline 14 & 9.00 & 25.00 & 0.50 & 83 & 84.41 \\
\hline 15 & 2.00 & 25.00 & 0.50 & 97 & 100 \\
\hline 16 & 5.50 & 78.64 & 1.00 & 93 & 92.20 \\
\hline 17 & 5.50 & 45.00 & 1.00 & 92 & 48.14 \\
\hline 18 & 9.00 & 25.00 & 1.50 & 46 & 92.20 \\
\hline 19 & 5.50 & 45.00 & 1.00 & 90 & \\
\hline
\end{tabular}




\section{Result and discussion}

\subsection{Regression model and statistical analysis}

The CCD method has been successfully used for optimizing affecting factor that influenced on the percentage of amoxicillin removal. For the best response of system, the experimental results were analyzed through RSM to obtain an empirical model. The regression model equations (secondorder polynomial) relating the removal efficiency of amoxicillin and related parameters were developed as Equation 3:

$$
\begin{gathered}
\text { \%Removal }=+35.00926+7.71191 \times \mathrm{pH}+ \\
0.91252 \times \mathrm{T}+23.48479 \times \text { Dose }-7.14286 \mathrm{e}^{-} \\
{ }^{004} \times \mathrm{pH} \times \mathrm{T}+0.38571 \times \mathrm{pH}^{*} \times \text { Dose }+5 . \mathrm{e}^{-3} \times \mathrm{T} \times \text { Dose- } \\
0.68596 \times \mathrm{pH}^{2}-0.013048 \times \mathrm{T}^{2}-8.99753 \times \text { Dose }^{2}
\end{gathered}
$$

\section{(Eq. 3)}

The coefficients of Equation 3 are determined by using software Design-Expert 8 . The optimal parameters are as follows: $\mathrm{pH}=4.68$, the adsorbent dosage $=1.5 \mathrm{~g}$, and the temperature $=48.90^{\circ} \mathrm{C}$.
The model prediction of the amoxicillin removal was obtained \%99.48 while the experimental amount of removal efficiency achieved $\% 99$. These results confirmed that the RSM could be effectively applied to optimize the factors and parameters in complex processes. The term of encoded factor expressed relation between the independent variables and dependent response of system. Apart from the line are effects of the parameter for the amoxicillin removal, the RSM also gives an insight in to the quadratic and interaction effect of the parameters. Table 2 showed the results of regression analysis of obtained quadratic model. The $\mathrm{F}$-values and $\mathrm{p}$-values are related to significant of each coefficient (Table 2). High magnitude of the F-values and small magnitude of the p-values indicated that corresponding coefficients was more significant. Also, Values of "probe $>$ F" less than 0.0500 implied high significant regression at 95 percent confidence level. According to the F-value and p-values, the amount of adsorbent was

\begin{tabular}{|c|c|c|c|c|c|}
\hline \multirow[b]{2}{*}{ Source } & \multirow[b]{2}{*}{ sum of square } & \multicolumn{2}{|c|}{ Mean } & \multicolumn{2}{|c|}{ P-value } \\
\hline & & df & Square & F Value & Prob $>$ F \\
\hline Model & 3120.63835 & 14 & 222.902739 & 148.517383 & $<0.0001$ \\
\hline A-pH & 84.4231475 & 1 & 84.4231475 & 56.2501161 & $<0.0001$ \\
\hline B-adsorbent dose & 537.787036 & 1 & 537.787036 & 358.320959 & $<0.0001$ \\
\hline C-temperature & 0.66785645 & 1 & 0.66785645 & 0.44498463 & 0.5091 \\
\hline D-time & 116.402257 & 1 & 116.402257 & 77.5574075 & $<0.0001$ \\
\hline $\mathrm{AB}$ & 0.01125 & 1 & 0.01125 & 0.00749574 & 0.9315 \\
\hline $\mathrm{AC}$ & 25.56125 & 1 & 25.56125 & 17.0311499 & 0.0002 \\
\hline $\mathrm{AD}$ & 4.5 & 1 & 4.5 & 2.99829525 & 0.0922 \\
\hline $\mathrm{BC}$ & 15.40125 & 1 & 15.40125 & 10.2616655 & 0.0029 \\
\hline $\mathrm{BD}$ & 29.645 & 1 & 29.645 & 19.7521028 & $<0.0001$ \\
\hline $\mathrm{CD}$ & 26.645 & 1 & 26.645 & 17.7532393 & 0.0002 \\
\hline $\mathrm{A}^{\wedge} 2$ & 1107.54922 & 1 & 1107.54922 & 737.946571 & $<0.0001$ \\
\hline $\mathrm{B}^{\wedge} 2$ & 225.03502 & 1 & 225.03502 & 149.938096 & $<0.0001$ \\
\hline $\mathrm{C}^{\wedge} 2$ & 745.166816 & 1 & 745.166816 & 496.495584 & $<0.0001$ \\
\hline $\mathrm{D}^{\wedge} 2$ & 897.389678 & 1 & 897.389678 & 597.919825 & $<0.0001$ \\
\hline Residual & 52.52985 & 35 & 1.50085286 & & \\
\hline Lack of Fit & 5.00385003 & 10 & 0.500385 & 0.26321645 & 0.9840 \\
\hline Pure rror & 47.526 & 25 & 1.90104 & & \\
\hline
\end{tabular}
found more effective on the adsorption process of amoxicillin. The "Lack of Fit F-value" of 0.26

Table 2. ANOVA analysis for removal of amoxicillin 
indicated that the Lack of Fit is not significant.

The fitness of the model was expressed by the determination coefficient $\left(\mathrm{R}^{2}\right)$. The "Pred R-quared" of 0.9848 is in agreement with the "Adj R-Squared" of 0.9768. "Adeq Precision" expressed the value of signal to noise ratio. A ratio greater than 4 is favorable. In this case "Adeq Precision" of 30.63 indicates an adequate signal. Thus, as a result of the statistical analysis, quadratic model was found suitable for demonstrate the adsorption process and useful for developing empirical relationships. Removal efficiency of amoxicillin was sensitively depended to the amount of adsorbent. The removal efficiency was sharply increased when the amount of adsorbent increased from $0.5 \mathrm{~g}$ to $1.5 \mathrm{~g}$. The increase in yield due to increase in adsorbent dosage was more dominated

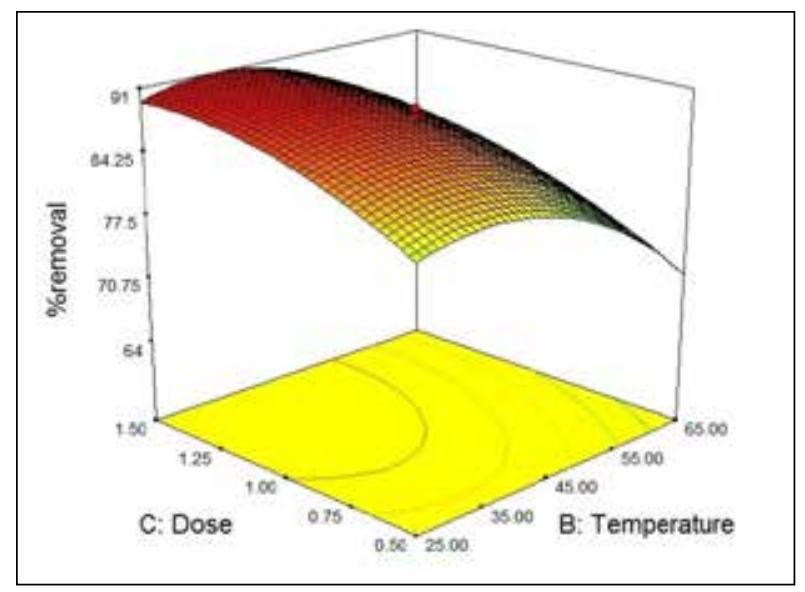

than other significant factors. The $\mathrm{pH}$ of the solution was another factor that influenced the response of system. As can be seen on Figure 1, when the $\mathrm{pH}$ increased from 2 to 5 , the removal efficiency of amoxicillin was increased. Temperature is a key factor which effect on adsorption process. In this study, effect of temperature on removal efficiency of amoxicillin was investigated. Results showed that by increasing of temperature, the removal efficiency of amoxicillin decreased and in $48^{\circ} \mathrm{C}$ the highest removal efficiency was obtained.

The parity plot are presented in Figure 2. As shown in Fig. 2, there was a satisfactory correlation between the observed and fitted values. In addition, a normal distribution of residual were observed in Figure 2 which indicated the data points can be formed approximately straight line.

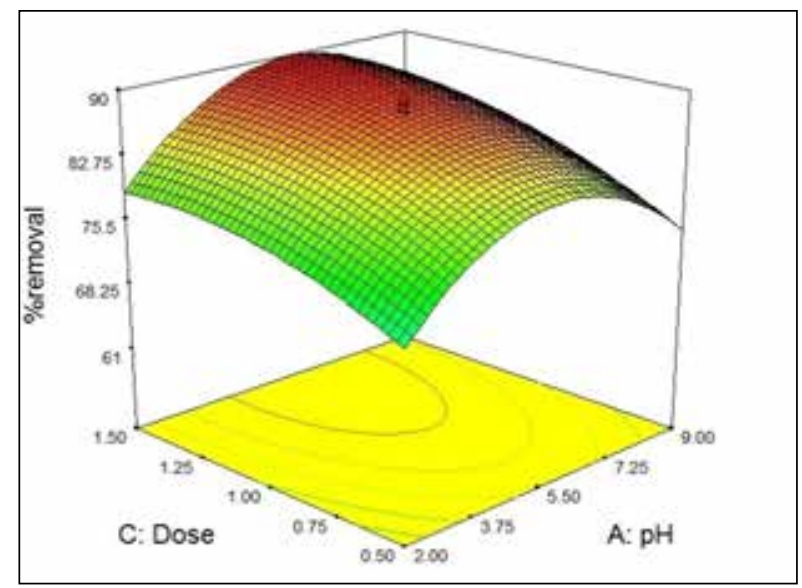

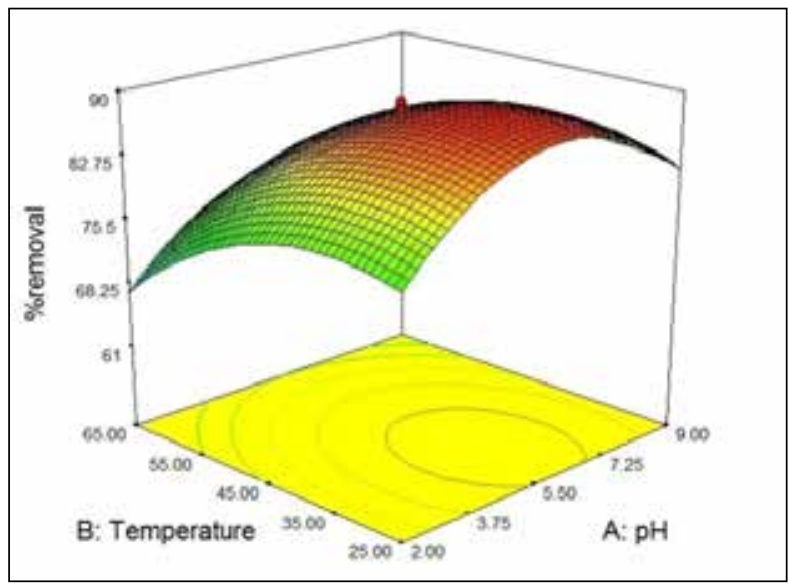

Fig.1. Response of surface by CCD method 


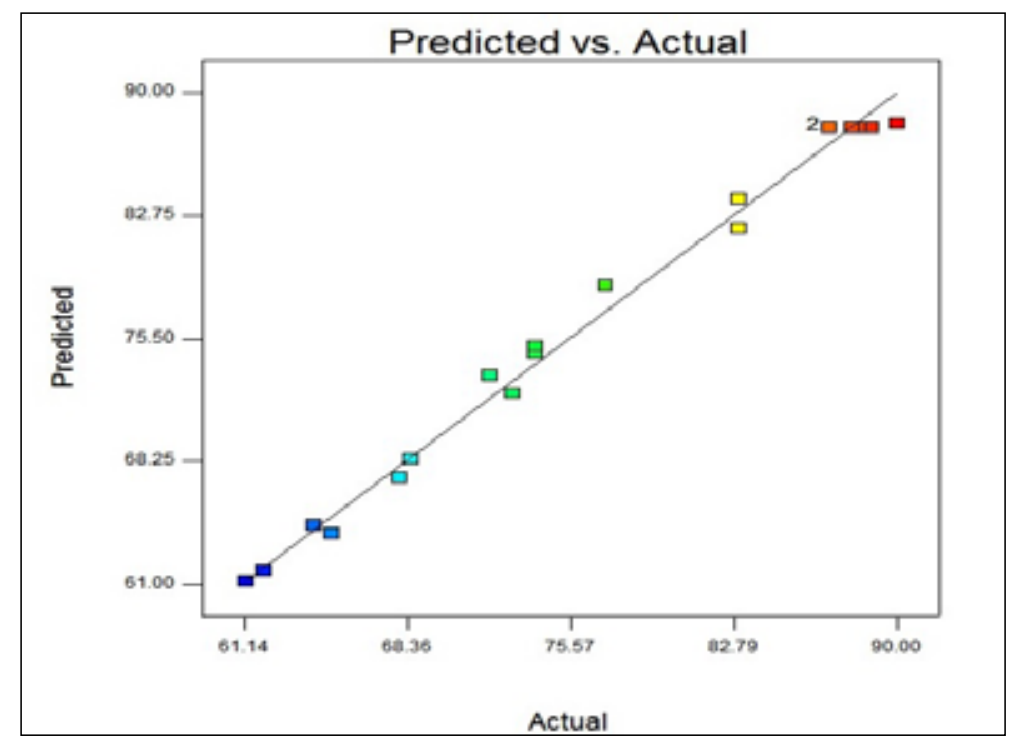

Fig. 2. The normal probability plot of the residuals and parity plot show the correlation between the observed and predicted values.

Table 3. Adsorption of amoxicillin in real samples based on magnetic bentonite nanocomposite using response surface methodology

\begin{tabular}{|c|c|c|c|c|}
\hline Sample & Added $\left(\mathrm{mg} \mathrm{L}^{-1}\right)$ & Initial Amount (mg $\left.\mathbf{L}^{-1}\right)$ & Final Amount (mg L L $\left.{ }^{-1}\right)$ & Recovery (\%) \\
\hline \multirow{2}{*}{ Sample 1} & -------- & -------- & $56.6 \pm 2.1$ & --------- \\
\hline & 50 & -------- & $105.4 \pm 4.7$ & 97.6 \\
\hline \multirow{2}{*}{ Sample 2} & --------- & --------- & $66.3 \pm 2.8$ & --------- \\
\hline & 50 & -------- & $117.1 \pm 5.6$ & 101.4 \\
\hline \multirow{2}{*}{ Sample 3} & -------- & -------- & $23.9 \pm 0.9$ & -------- \\
\hline & 20 & -------- & $43.5 \pm 1.7$ & 98.0 \\
\hline \multirow{2}{*}{ CRM 1} & - ------- & 23.4 & $22.2 \pm 1.1$ & 94.8 \\
\hline & 20 & -------- & $41.6 \pm 1.9$ & 97.0 \\
\hline \multirow{2}{*}{ CRM 2} & --------- & 58.9 & $56.8 \pm 2.3$ & 96.4 \\
\hline & 50 & -------- & $107.2 \pm 5.1$ & 100.8 \\
\hline \multirow{2}{*}{ CRM 3} & -------- & 102.5 & $98.7 \pm 4.8$ & 98.9 \\
\hline & 100 & -------- & $96.9 \pm 4.6$ & 96.9 \\
\hline \multirow{2}{*}{ CRM 4} & --------- & 47.1 & $48.2 \pm 1.7$ & 102.3 \\
\hline & 50 & -------- & $96.8 \pm 1.7$ & 97.2 \\
\hline
\end{tabular}

Mean of three determinations \pm standard deviation $(\mathrm{P}=0.95, \mathrm{n}=5)$

Sample 1: Wastewater Drug Factory

Sample 2: Wastewater Hospital

Sample 2: Wastewater Drug Razi

CRM 1, 2, 3 and 4 analysis with HPLC-MS with concentration of 23.4, 58.9, 102.5 and 47.1 respectively 


\subsection{Application of proposed methods to real sample}

To verify the potential application of proposed method to real samples, three real wastewater samples were selected and used by proposed procedure. Different concentrations of amoxicillin include 100, 150 and $200 \mathrm{mg} \mathrm{L}^{-1}$ were spiked to the samples and removal efficiency of amoxicillin was tested using proposed methods. Results are shown in Table 3. As expected, the magnetic bentonite nanocomposite has good recovery for adsorption of the spiked amoxicillin from all three real samples.

\section{Conclusions}

In this work, a magnetic bentonite nanocomposite was synthesized and applied for adsorption of amoxicillin from wastewater. A central composition design was applied for study of the effects of parameters such as; $\mathrm{pH}$, temperature and amount of adsorbent which was influenced on the removal efficiency of amoxicillin. A quadratic model was solved and developed to correlate the independed variables and the response of system. Through the analysis of response surfaces, was found that amount of adsorbent was most significant variable on removal efficiency of amoxicillin by HPLC. Process optimization was performed and results showed that the experimental data were found to agree with the predicted values.

\section{References}

[1] T.H. Le, C. Ng, Removal of antibiotic residues, antibiotic resistant bacteria and antibiotic resistance genes in municipal wastewater by membrane bioreactor systems, Water res., 145 (2018) 498-508.

[2] W. Yan, Y. Xiao, W. Yan, The effect of bioelectrochemical systems on antibiotics removal and antibiotic resistance genes: a review, Chem. Eng. J., 358 (2019) 14211437.

[3] S. Ren, C. Boo, N. Guo, Photocatalytic reactive ultrafiltration membrane for removal of antibiotic resistant bacteria and antibiotic resistance genes from wastewater effluent,
Environ. Sci. Technol., 52 (2018) 8666-8673.

[4] Z. Cao, X. Liu, J. Xu, J. Zang, Removal of antibiotic florfenicol by sulfide-modified nanoscale zero-valent iron, Environ. Sci. Technol., 51 (2017) 11269-11277.

[5] N. Li, G.-P. Sheng, Removal of antibiotic resistance genes from wastewater treatment plant effluent by coagulation, Water Res., 111 (2017) 204-212.

[6] Y. Zhou, Q. Yang, D. Zhang, N. Gan, Q. $\mathrm{Li}$, Detection and removal of antibiotic tetracycline in water with a highly stable luminescent MOF, Sensors and Actuators B: Chem., 262 (2018) 137-143.

[7] Y. Hong, C. Li, G. Zhang, Efficient and stable $\mathrm{Nb}_{2} \mathrm{O}_{5}$ modified g-C3N4 photocatalyst for removal of antibiotic pollutant, Chem. Eng. J., 299 (2016) 74-84.

[8] C. Guo, $\mathrm{H}_{2} \mathrm{O}_{2}$ and/or $\mathrm{TiO}_{2}$ photocatalysis under UV irradiation for the removal of antibiotic resistant bacteria and their antibiotic resistance genes, J. Hazard. Mater., 323 (2017) 710-718.

[9] C. Hong, P.-Y. Hong, Removal of antibioticresistant bacteria and antibiotic resistance genes affected by varying degrees of fouling on anaerobic microfiltration membranes, Environ. Sci. Technol., 51 (2017) 1220012209.

[10] B. Kayan, B. Gözmen, Degradation of Acid Red 274 using $\mathrm{H} 2 \mathrm{O} 2$ in subcritical water: Application of response surface methodology, J. Hazard. Mater., 201 (2012) 100-106.

[11] S. Tang, D. Yuan, Y. Rao, N. Li, Persulfate activation in gas phase surface discharge plasma for synergetic removal of antibiotic in water., Chem. Eng. J., 337 (2018) 446-454.

[12] F.S. Hashem, Removal of methylene blue by magnetite covered bentonite nano-composite, Eur. Chem. Bull., 2 (2013) 524-529. 